\title{
Improvement methods for solving the distribution network reconfiguration problem
}

\section{Ha Duc Nguyen ${ }^{1}$,}

Ilgiz Mirgalimovich Valeev ${ }^{2}$

${ }^{1}$ Institute of Management, Automation and Information Technologies, Faculty of Management and Automation, Department of Electric Drive and Electrical Engineering,

Kazan National Research Technological University, Sibirsky Trakt 12, building "L",

420029, Kazan, Russia

Email:electroprivod@mail.ru

${ }_{2}^{2}$ Institute of Electric Power Engineering and Electronics,

Department of Electrical Systems and Grid, Kazan State Power Engineering University,

Krasnoselskaya St. 51,

420066, Kazan, Russia

Email: esis.kgeu@bk.ru
The paper presents methods for solving the distribution network reconfiguration problem based on heuristic algorithms. In particular, the study solved the distribution network reconfiguration problem for active power losses reduction. The application of the method to a sample network proved effective compared to other algorithms, especially in case of large-scale and complex systems. In addition, the paper considers the influence of the location and capacity of distributed generations on the distribution network reconfiguration problem in different cases. The results show that the distribution network reconfiguration problem combined with optimization location and size of distributed generations is the most efficient solution for minimizing power loss and enhancing voltage profile. The proposed methods have been also successfully applied in the small- and medium-scale practical radial distribution networks. The simulation results show that the proposed methods can be used as reference materials for network reconfiguration problems with single and multi-objectives.

Keywords: reconfiguration, heuristic algorithms, increase function, power loss, distribution network

\section{INTRODUCTION}

The power system consists of four main components: power plant, transmission network, distribution network, and load. In these four components, the distribution network plays a particularly important role, which directly affects the reliability, quality, and cost of electricity supply.

The distribution network is usually operated in an open mode, or radial structure, meaning that there is no closed loop in the single-line diagram. The open structure has many advantages over the closed-loop operation, such as easy mesh protection, small fault currents, easy voltage adjustment, and power flow distribution. However, by operating at low voltage and high currents, the distribution network often has large power losses and voltage drop [1].

Although the distribution network operates as radial structures to improve the reliability, there are many normally opened switches on the distribution networks that can be connected to other networks. During a fault in the distribution 
network, these normally opened switches are used for to fault isolation and service restoration. In addition, on the radial distribution network, there are also normally closed switches. These switches may change position upon request.

Distribution network reconfiguration (DNR) is the process of changing the structure of a distribution network. The branches are frequently reconfigured by changing the open/closed state of the normally closed and normally open switches while satisfying the constraints according to the operator's purpose, which contains technical constraints such as [2]:

- it has an open operating structure;

- all loads are provided with electricity, with pressure drop within the allowed range;

- the relays protection system must be changed suitably;

- lines, transformers, and other equipment are not overloaded.

The problem of distribution network reconfiguration is the status control of switching equipment in the distribution network that, in some operation cases, ensures the minimal cost of the operation network [3]; the minimal power loss $[3,4]$; the reconfiguration distribution network to balance load (among lines and transformers at stations) and improve the loading capacity of electrical network $[5,7]$.

It is necessary to recover the structure of an electrical network after an incident or power cutoff for repairing [6] and determine the structure by some objectives such as the highest loading balance, minimal power loss, loading transmission and voltage drop at the end of network concurrently, and effects of DG on DNR [1].

There are many methods to solve the DNR problem for different purposes, but they all use the reconfiguration problem to reduce power loss as the main module in the problem-solving process. The distribution system reconfiguration for power loss reduction was first proposed by Merlin and Back [7]. To solve the distribution network reconfiguring problem with the objective of minimizing losses in the network configuration with the mesh network, first all the switches normally open in the loop were closed, then opened respectively in order to obtain the distribution network with a radial configuration. However, this method has the defect that if the number of switches in a closed loop is $n$, the number of iterations calculated will be $2^{\mathrm{n}}$. To overcome this defect, Shirmohammadi and Hong [8] proposed an improvement heuristic algorithm. This algorithm only considers the state of the switch with the smallest current flowing through, thus reducing the number of calculation iterations, but it still takes a long time to find the most optimal configuration. Civanlar et al. [9] used a heuristic technique to solve the distribution network reconfiguration problem to reduce line losses using techniques called 'branch exchange'. When opening any selected switch, it will correspond to closing another switch to ensure that the radial configuration of the distribution network enterprise is guaranteed. Then, they usually fall into local minima and use algorithms of artificial intelligence and evolution, among which the most effective one is a genetic algorithm $[4,10,11]$.

For mathematics, the reconfiguration network is the discrete nonlinear programming by the power flow running on branches $[9,11]$. The goal of the reconfiguration is to minimize the active power losses during the power flow.

Minimal function

$$
F_{(\Delta P)}=\sum_{i=1}^{N} \sum_{j=1}^{N} C_{i j} \cdot I_{i j} \cdot R_{i j}^{2}=\sum_{i=1}^{N} \sum_{j=1}^{N} C_{i j} \cdot \Delta P_{i j} \rightarrow \min .
$$

These constraints are expressed by

$$
\begin{aligned}
& \sum_{i=1}^{N} S_{i j}=S_{j,}, \\
& S_{i j} \leq S_{i j \max }, \\
& \Delta U_{i j} \leq \Delta U_{i j \max }, \\
& \sum_{\forall f_{T}}^{N} S_{f_{T}} \leq S_{f_{T T} \max }, \\
& \prod_{\forall f_{T}} \lambda_{f_{T}}=1,
\end{aligned}
$$

where

$N$ is the number of load nodes,

$C_{i j}$ is weighting factors of power loss in the considered section $i j$,

$\Delta P_{i j}$ is power losses in the branch from node $i$ to node $j, \mathrm{~kW}$, $\mathrm{kVA}$,
$S_{i j}$ is power flow in the considered section $i j$, 
$S_{j}$ is total power demand of the $j^{\text {th }}$ node, $\mathrm{kVA}$, $i j, \mathrm{kV}$,

$\Delta U_{i j}$ is voltage drop on the considered section

$f_{T}$ is lines powered by transformer $T$,

$S_{f T}$ is power flow in the branch, $\mathrm{kW}, \lambda_{f T}$ is equal to 1 if the branch $i j$ is powered, equal to 0 if otherwise.

The objective function (1) represents the total losses across the distribution network. One can simplify the objective function by considering power flow on the branch only if the component power load and voltage at the load node are constant. The objective function is interrupted, which makes it difficult to solve the problem of DNR by traditional mathematical analysis [5].

When approaching electrical reconfiguration in the distribution network, scientists determine that mathematical analytics is not as effective as a search algorithm $[4,11,14]$. Search algorithms used in the electrical DNR can be divided into three main groups: a heuristic search algorithm that combines with optimal algorithm [4]; an algorithm only using a heuristic rule in an expert system $[10,15,16]$; and methods of swarm intelligence [17].

In general, the heuristic search algorithms analysed above are based on the 'Greedy' principle. Therefore, it is easy to implement the algorithm when using DNR with a small number of switches to consider. But for medium and large DNs, with great nodes, branches and switches equipped, they can hardly converge to the global optimal solution. Intelligent algorithms can direct the searching process to the global optimum at the one hundred percent probability in theory [18]. But they all inevitably involve a large number of computation requirements and really have a lot of control parameters.

Therefore, the objective of the research is to build an algorithm for solving the DNR problem based on heuristic algorithms in order to reduce the loss in the condition of distributed generations (DG) being present. The results of this study will bring great economic efficiency and practical significance.

The layout of the article is divided into three parts. The first part describes the mathematical model of the distribution network. It then defines the objective function and constraint con- ditions determining the correlation between the parameters of the distribution network due to the effect of compensators and DG. The next part proposes a new method for solving the DNR problem by building a new objective function called the reduction function of the power loss target, thereby building the optimal search algorithm to solve the problem. It is applied to the computation on the actual DNR according to IEEE standards.

\section{PROBLEM STATEMENT}

\section{Mathematical description of load redistribution operation}

Convention:

- $I_{p, i}, I_{q, i}$ : action and reactive current of the branch $I ; R_{i}$ : electrical resistance of branch $i$,

- the coefficient $\mathrm{k}$ as electrical switch number to ensure open electrical network operation. In the branch, there is an open electrical switch at the $j^{\text {th }}$ with the sign: $M N_{j}$ and $j=1 \ldots \mathrm{k}$,

- $V_{j h}$ : the set of crossing branches between loop $j$ and loop $h$,

$-V_{\text {ji,loop: }}$ : the set of branches under the loop $j$,

$-R_{j, \text { loop }}$ : resistance of the $j^{\text {th }}$ loop,

$-M N_{j}$ : the branch with the open switch of the $j^{\text {th }}$ loop.

Indicator $A_{i j}$ states the correlation between the $j^{\text {th }}$ loop and natural distribution direction towards the $i^{\text {th }}$ branch in the open network.

$A_{i j}=1$ : when the direction of $j$-loop is the same as those of $I_{p, i}$ and $I_{q, i}$

$A_{i j}=-1$ : when the direction of $j$-loop is counter to those of $I_{p, i}$ and $I_{q, i}$

$A_{i j}=0$ : when the $i^{\text {th }}$ branch does not belong to j-loop.

Let us consider a simple distribution network with a single source and a closed loop at the open branch MN (Fig. 1), or $I_{p}^{M N}=0$ and $I_{q}^{M N}=0$. Thus, the determination of the open switch on the network with the smallest power loss can be considered the amount of power flow to be transferred from the existing open switch to the new switch. Assuming that the result is a switch to On in MN branch and a switch to Off in the other branch (for example, AB), the change in load redistribution can be similar to the injection/absorption current of the two poles in the branch $\mathrm{MN}\left(I^{b r}=I_{p}+j I_{q}\right)$ until the current in the branch 


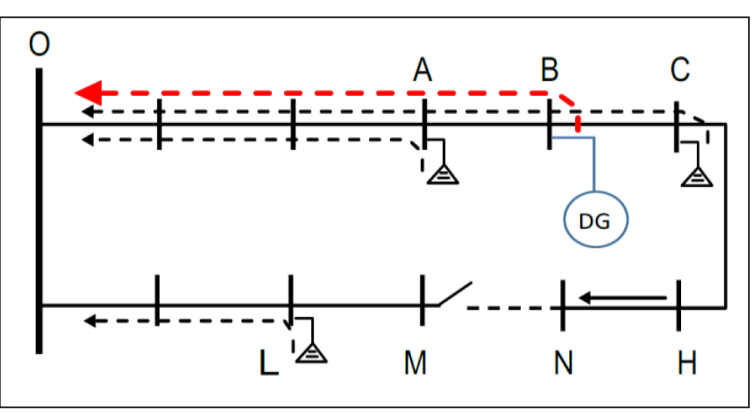

Fig. 1. Open-loop distribution network with compensator and DG

$\mathrm{AB}$ is zero [8]. To describe the function $\Delta P$, depending on the amount of transmitted power or the power flow, it is possible to use the injection/absorption method at the open switch on the branch MN with a same current $I^{M N}$ (Fig. 2).

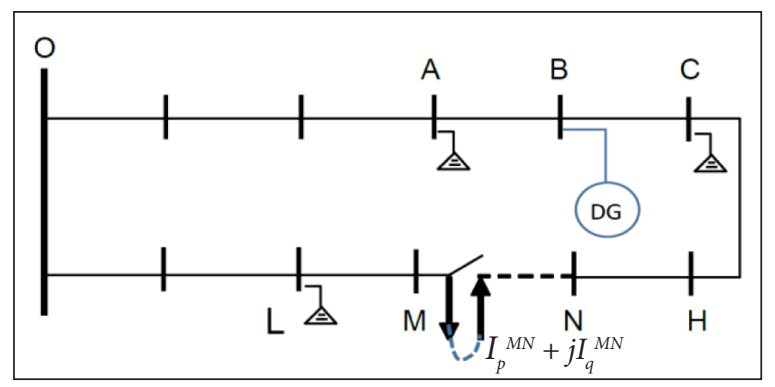

Fig. 2. Operation to open/close load distribution

The necessary condition for (1) is minimized by the following variables $I_{p}$ and $I_{q}$ :

$$
\begin{aligned}
& \frac{\partial \Delta P^{\text {new }}}{\partial I_{p}^{M N}}=0, \\
& \frac{\partial \Delta P^{\text {new }}}{\partial I_{q}^{M N}}=0 .
\end{aligned}
$$

From Eqs. (7) and (8) current $I_{p}$ and $I_{q}$ are represented in two expressions (9) and (10):

$$
\begin{aligned}
& I_{p}^{M N}=\frac{1}{R^{\operatorname{loop}}}\left[\sum_{\substack{i=1 \\
i \in O M}}^{N} I_{p, i} R_{i}-\sum_{\substack{i=1 \\
i \in O M}}^{N} I_{p, i} R_{i}\right] \\
& +\frac{1}{R^{\operatorname{loop}}} I_{p, B}^{D G} \sum_{\substack{i=1 \\
i \in O M}}^{N} R_{i} \\
& I_{q}^{M N}=\frac{1}{R^{\operatorname{loop}}}\left[\sum_{\substack{i=1 \\
i \in O M}}^{N} I_{q, i} R_{i}-\sum_{\substack{i=1 \\
i \in O N}}^{N} I_{q, i} R_{i}\right]+\frac{1}{R^{\operatorname{loop}}} I_{q, B}^{D G} \sum_{\substack{i=1 \\
i \in O B}}^{N} R_{i}
\end{aligned}
$$

$$
+\frac{1}{R^{\text {loop }}}\left[I_{q, A}^{\mathrm{comp}} \sum_{\substack{i=1 \\ i \in O A}}^{N} R_{i}+I_{q, A}^{\mathrm{comp}} \sum_{\substack{i=1 \\ i \in O C}}^{N} R_{i}-I_{q, L}^{\mathrm{comp}} \sum_{\substack{i=1 \\ i \in O L}}^{N} R_{i}\right]
$$

Expression (9) shows that the $I_{q}^{M N}$ depends on the load and the power of the DG, regardless of the reactive power compensation. In addition, the expression (10) indicates that the $I_{q}^{M N}$ depends not only on the load impedance, the reactive power generated by the DG but also on the capacity and location of the capacitor compensator.

In mathematical terms, the objective function to reduce the power loss in a general distribution network is determined as

$$
\begin{aligned}
& \Delta P=\sum_{i=1}^{N}\left(I_{p, i}-\sum_{g=1}^{G} C_{i, g} I_{p, g}^{D G}-A_{i j} \sum_{j=1}^{K} I_{p, 1}^{M N}\right)^{2} R_{i} \\
& +\sum_{i=1}^{N}\left(I_{q, i}-\sum_{g=1}^{G} C_{i, g} I_{q, g}^{D G}-\sum_{l=1}^{L} B_{i l}{ }_{q, l}^{\mathrm{comp}}-A_{i j} \sum_{j=1}^{K} I_{q, j}^{M N}\right)^{2} R_{i} \\
& +\sum_{j=1}^{K}\left(I_{p, j}^{M N}\right)^{2} R_{i}^{M N}+\sum_{j=1}^{K}\left(I_{q, j}^{M N}\right)^{2} R_{i}^{M N},
\end{aligned}
$$

where

- N, K, G, L: a number of nodes, loops, DG, and compensators in the distribution network,

- $R j^{M N}$ : the resistance of the branch with the open switch (MN) on the $j^{\text {th }}$ loop,

- $A_{i j}$ an index that describes the relationship direction between the $j$-loop and the $i$-branch, with values $(-1,0,+1$ : respectively, inverse, non-relational, and the same direction),

$-B_{i l}$ an index that describes the relationship position between the $l$-capacitor and the $i$-branch, with values $(0,+1$ : respectively, non-relational, and position $l$-capacitor after $i$-branch calculated from source),

$-C_{i l}$ an index that describes the relationship position between the $g$-DG and the $i$-branch, with values $(0,+1$ : respectively, non-relational, and position $g$-DG after $i$-branch calculated from source).

The condition required to (11) reaches the minimum according to the $I^{M N}$ variables is

$$
\begin{aligned}
& \frac{\partial \Delta P^{\mathrm{new}}}{\partial I_{p, j}^{M N}}=0, \\
& \frac{\partial \Delta P^{\mathrm{new}}}{\partial I_{q, j}^{M N}}=0,
\end{aligned}
$$


or

$$
\begin{aligned}
& I_{p, j}^{M N}=\frac{-A_{i j} \sum_{i=1}^{N} I_{p, i} R_{i}}{R_{j}^{\text {loop }, M N}}+\frac{-A_{i j} \sum_{g=1}^{G} C_{i, g} I_{p, g}^{D G} R_{i}}{R_{j}^{\text {loop }, M N}}, \\
& I_{q, j}^{M N}=\frac{-A_{i j} \sum_{i=1}^{N} I_{q, i} R_{i}}{R_{j}^{\text {loop }, M N}}+\frac{A_{i j} \sum_{g=1}^{G} C_{i, g} I_{p, g}^{D G} R_{i}}{R_{j}^{\text {loop }, M N}} \\
& +\frac{A_{i j} \sum_{l=1}^{G} B_{i, l} I_{q, g}^{D G} R_{i}}{R_{j}^{\text {loop }, M N}} .
\end{aligned}
$$

\section{Comments and evaluation}

In the initial distribution network configuration, if a current is injected/withdrawn at open switches as Eqs. (12) and (13), it will create a loop current through the branches. Then, power loss function $\Delta P$ at Eq. (11) will reach the minimum.

The value of the loop current depends on the selected switch on loop injection/absorption current. Theoretically, if a switch selected for the loop current to injection/absorption current is equal to zero, it is the optimal point.

The first part in expression (14) is the sum of the voltage drops in branches of the $j$ independent circuit if the circuit is resistance. This shows that the optimum value of obtained current under Eqs. (12) and (13) is the branch current of the closed distribution network. When all electrical switches are closed, the total power losses in the distribution network are minimal.

In Eq. (15), the effect of compensating capacitors on currents $I_{q}{ }^{\text {comp }}$ may have an impact on the small distribution network but $I_{q}{ }^{\text {comp }}$ will be greatly reduced on the large and complex distribution network because the $A_{i j}$ and $B_{i j}$ can interact and compensate each other. In other words, the structure of the large distribution network will not change significantly when the minimum of power loss is taken into account when considering the effect of all capacitors on the network. This is consistent with the qualitative conclusions in $[9,18]$.

When there are DG resources involved in the distribution network, the optimal expression for the received current will be added to the second part (in Eqs. (14) and (15)).

\section{A NEW METHOD FOR SOLVING DNR PROBLEM}

\section{Objective function of the problem}

As mentioned above, the current of the additional load on the distribution network without DG and the DG current impact the network. $I_{p}{ }^{M N}$ and $I_{p}{ }^{M N}$ defined by Eqs. (12) and (13) are the condition of minimizing $\Delta P$. Reducing this value will make the objective function one decrease. Thus, Eqs. (12) and (13) can be rewritten as follows (ignoring the impact of reactive power compensation capacitors on a large and complex distribution network):

$$
\left\{\begin{array}{l}
I_{p, j}^{M N} \cdot R_{j}^{\text {loop }, M N}=-A_{i j} \sum_{i=1}^{N} I_{p, i} R_{i}+A_{i j} \sum_{g=1}^{G} C_{i, g} I_{p, g}^{D G} R_{i}+\alpha_{p, j} \\
I_{q, j}^{M N} \cdot R_{j}^{\text {loop }, M N}=-A_{i j} \sum_{i=1}^{N} I_{q, i} R_{i}+A_{i j} \sum_{g=1}^{G} C_{i, g} I_{q, g}^{D G} R_{i}+\beta_{p, j} .
\end{array}\right.
$$

Reducing this value will make the objective function one (11) decrease. However, the reduction of $\Delta P$ from Eq. (11) will face some difficulties due to the interaction between branch current and DG impacting the distribution network; moreover, we also notice that when $I_{p}{ }^{M N}$ and $I_{p}{ }^{M N}$ are the smallest, power loss will be the best. If we put $G=\sum\left[\alpha_{p, j}^{2}+\beta_{q, j}^{2}\right]$ with $j=1 \ldots K$, then

$$
\begin{aligned}
& G=\sum_{j=1}^{K}\left[\left(I_{p, j}^{M N} R_{j}^{\text {loop, } M N}\right)^{2}+\left(I_{q, j}^{M N} R_{j}^{\text {loop }, M N}\right)^{2}\right] \\
& =\sum_{j=1}^{K}\left(I^{M N} R_{j}^{\text {loop }, M N}\right)^{2} \rightarrow \min .
\end{aligned}
$$

The reduction of $G$ from Eq. (17) will face some difficulties due to the interaction between branch current and DG impacting the distribution network. These observations make it clear that the operating structure of the distributed network has the smallest power loss in case of the smallest value of $G$ on the open-loop distribution network.

\section{A new algorithm}

The new algorithm of experience rule for the distribution network reconfiguration problem is proposed in Fig. 3:

Rule 1: Close all switches forming a closed net, where the loss going through the closed loop will be the smallest. 


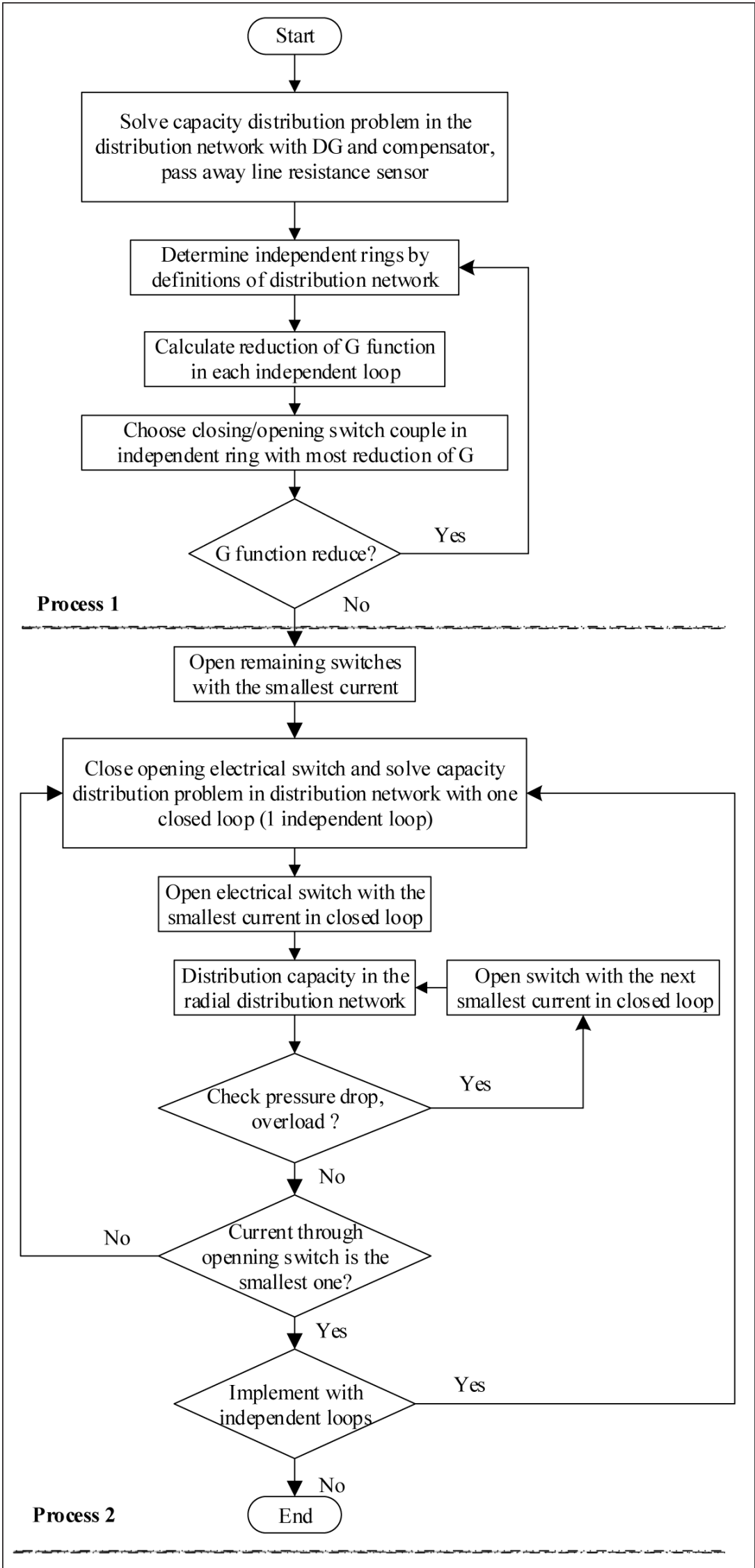

Fig. 3. Algorithm of DNR with $D G$, to find the smallest $\triangle P$ 
Rule 2: Calculate the function $G$ following with (17), make a list with descending $\Delta G$ and open a pair of electrical switches in the independent loop, starting with the largest $G$ loop.

Rule 3: When a close/open switch is an independent switch, in order to reduce power loss, it will open the switch with the smallest electric current and close the switch with the maximum one.

The calculation of $G$ function is not complicated and faster than the direct calculation of power flows. Applying the $G$ function allows showing the last configuration to have an increase of $\Delta P$ at least compared to the closed network, as there is a comparison of $G$ functions at all independent loops across the distribution network.

This algorithm has the following characteristics. The objective function shown in this section takes into account the resistance factor of the independent loop. This is a new objective function (previous studies [13] often used to reduce the function $\left(\triangle P=I^{2} R\right)$ (directly, or simply to find the branch to have the smallest current). Function $G$ is meaningful as a comparison criterion, so finding the optimal distribution network configuration has been proposed to determine the power loss of increase function ( $G$ function) on the distribution network. This enables the algorithm to be stronger and faster in finding optimal configurations with $\Delta P$ increasing less than the loop network.

The increase in function $G$ was considered to be the value of power loss and the resistance factor of the distribution network $\left(R_{j}^{\text {loop}}\right)$, and the interactions between the electric switches, effects of DG on the distribution network. This is the difference in comparison with previous studies. If we ignore the resistance factor (the 'distance' of the electrical switch compared to the power supply), we usually select the branch with the fewest lines in the distribution network to open first. This leads to open electric switches, which are far from the power source and, in fact, are not normally open (because if they are open, the rear loads will not have electricity). Therefore, finding optimum $\Delta P$ can avoid the local minimum and does not take time to re-examine whether all loads are being supplied with electricity. It also makes sense to com- pare the value of the function $\Delta P$ when there are many competitive pairs in the distribution network.

\section{SIMULATION AND EVALUATION OF RESEARCH RESULTS}

\section{Simulation of researching results}

Using the algorithm of the proposed method is applied to solve the DNR on three distribution networks according to IEEE standards. At the same time, the results obtained will be compared with some of the other results on the same configuration $\mathrm{DN}$ to demonstrate the performance and highlight the quality of the proposed algorithm.

\section{6-node system IEEE}

Considering the distribution network of 16 nodes with 21 branches, there are 6 open switches and 2 DGs proposed by Celli et al. [21].

In distribution networks, there are $2 \mathrm{DG}$ with the capacity of $450 \mathrm{~kW}$ (node 9) and $630 \mathrm{~kW}$ (node 13). The process of finding the operational configuration to the smallest $\Delta P$ was surveyed in two cases, namely, not connected and connected DG. The load graph of the nodes follows the general load graph of the system and the nodes are calculated for the peak load. The results of finding the optimal configuration are compared with those of $[9,19]$ and the calculated ones in the module TOPO to solve the problem of PSS/ ADEPT 5.0 to verify the advantages of the proposed algorithm.

The algorithm derived from performing simulations on the test system IEEE and comparing it with other research algorithm is presented in Table 1.

Table 1. Survey results on 16-node network without DG and comparing

\begin{tabular}{ccc}
\hline Open switch & $\boldsymbol{\Delta P}(\mathbf{k W})$ & Methods \\
\hline $2,8,9,15,16,20$ & 144.17 & Celli et al. [21] \\
\hline $2,7,16,20,10,19$ & 92.265 & Merlin and Back [7] \\
\hline $2,7,16,20,10,19$ & 93.265 & Civanlar et al. [9] \\
\hline $2,7,16,20,10,19$ & 92.265 & TOPO (PSS/ADEPT) \\
\hline $2,7,16,20,10,19$ & $\mathbf{9 2 . 2 6 5}$ & Proposed method \\
\hline
\end{tabular}


With the initial configuration, the normally open switches are $(2,8,9,15,16,20)$. Without a connection with DG, the total power loss of the network is $144.17 \mathrm{~kW}$. After applying the proposed algorithm, switches $(2,7,16,20,10,19)$ are opened and the total power losses are reduced to $92.265 \mathrm{~kW}$. Table 2 compares the results of different cases considered.

\section{3-node system IEEE}

The distribution network includes 33 nodes and 37 branches and 32 sectionalizing switches. The parameters are presented in [5], using 4 DG.
This system is often used as an example for testing the accuracy of DNR algorithms, since this is a complex network consisting of 5 nested loops, deeply structured. If the algorithm is not strong enough, the search process is easy to fall into the local minimum. In the initial structure, the system has 5 open switches $(37,33,35$, $34,36)$ respectively and form five independent loops.

Figure 4 shows the diagram of solving the distribution network in case of not connecting and connecting simultaneously with 4 DG in PSS/ ADEPT.

The parameters of DGs are shown in Table 3.

Table 2. Results of surveying summary on the distribution network with 16 nodes

\begin{tabular}{|c|c|c|c|c|c|}
\hline Open switch & $\Delta P(k W)$ & Methods & $\begin{array}{c}\text { DG1 - node } \\
9(\mathrm{~kW})\end{array}$ & $\begin{array}{c}\text { DG2 - node } \\
13(\mathrm{~kW})\end{array}$ & Remark \\
\hline $2,8,9,15,16,20$ & 144.17 & Celli et al. [21] & 0 & 0 & \multirow{3}{*}{ No DG } \\
\hline $2,17,16,20,10,19$ & 92.265 & TOPO & 0 & 0 & \\
\hline $2,17,16,20,10,19$ & 92.265 & Proposed method & 0 & 0 & \\
\hline $2,8,10,15,18,20$ & 76.14 & Celli et al. [21] & 450 & 630 & \multirow{3}{*}{ Have both DG } \\
\hline $2,17,18,20,10,19$ & 66.33 & TOPO & 450 & 630 & \\
\hline $2,17,18,20,10,19$ & 66.33 & Proposed method & 450 & 630 & \\
\hline $2,8,10,15,16,20$ & 102.6 & Celli et al. [21] & 450 & 0 & \multirow{3}{*}{$\begin{array}{l}\text { DG1 work and } \\
\text { DG2 rest }\end{array}$} \\
\hline $2,17,16,20,10,19$ & 83.71 & TOPO & 450 & 0 & \\
\hline $2,17,16,20,10,19$ & 83.71 & Proposed method & 450 & 0 & \\
\hline $2,9,10,15,18,20$ & 82.94 & Celli et al. [21] & 0 & 630 & \multirow{3}{*}{$\begin{array}{l}\text { DG1 rest and } \\
\text { DG2 work }\end{array}$} \\
\hline $2,17,18,20,10,19$ & 74.31 & TOPO & 0 & 630 & \\
\hline $2,17,18,20,10,19$ & 74.31 & Proposed method & 0 & 630 & \\
\hline
\end{tabular}

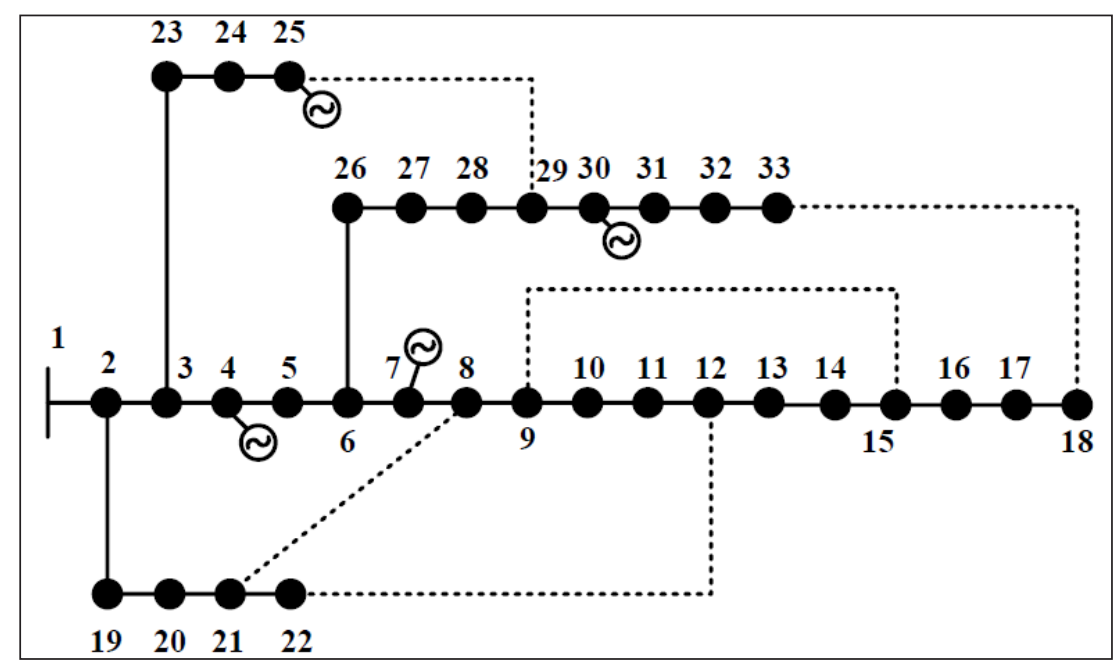

Fig. 4. The distribution network of 33 nodes 
Table 3. Parameters of DG

\begin{tabular}{c|c|c|c}
\hline No & Node & $\boldsymbol{P}(\mathbf{k W})$ & $\boldsymbol{Q}(\mathbf{k V a r})$ \\
\hline 1. & 4 & 50 & 37.5 \\
\hline 2. & 7 & 100 & 48.4 \\
\hline 3. & 25 & 200 & 96.9 \\
\hline 4. & 30 & 100 & 0 \\
\hline
\end{tabular}

Initial configuration not connected with the DG loses $203.679 \mathrm{~kW}$ capacity corresponding to the branch opening $(33,34,35,36,37)$. After performing the new optimized gain algorithm with the open switches $(7,37,9,14,32)$, power losses dropped to $138.876 \mathrm{~kW}$ after 8 loops.

When introducing DGs into the operation after applying the proposed algorithm, switches
$(7,28,9,14,32)$ are opened and the total power losses are reduced from $173 \mathrm{~kW}$ to $111.45 \mathrm{~kW}$ after 12 repeated loops. Results calculated and compared with previous studies are summarized in Table 4.

\section{9-node system IEEE}

The distribution system includes 69 nodes and 73 branches, 5 switches usually open and total load capacity is $3.802+\mathrm{j} 3.696 \mathrm{MW}$ [21]. Under normal operating conditions, the switches $(69,70,71$, $72,73)$ are opened and 3 DGs are connected to the network at nodes $(50,21,61)$.

With the initial configuration, the normally open switches are $(73,72,70,69,71)$. The total

Table 4. Comparison before and after performing DNR with proposed algorithm in 33-node system

\begin{tabular}{ccccc}
\hline Methods & Power loss (kW) & Open switch & Repeated loop \\
\hline & The system does not have DG & \\
\hline Initial & 203.679 & $33,34,35,36,37$ & - \\
\hline Proposed method & $\mathbf{1 3 6 . 8 7}$ & $7,9,14,32,37$ & - \\
\hline Srinivasa et al. [22] & 136.87 & $7,9,14,32,37$ & - \\
\hline The system has connection to DG (all 4 DG connected together) \\
\hline Initial & 173 & $33,34,35,36,37$ & 12 \\
\hline Proposed method & $\mathbf{1 1 1 . 4 5}$ & $7,9,14,28,32$ & - \\
\hline Srinivasa et al. [22] & 111.45 & $7,9,14,28,32$ & \\
\hline
\end{tabular}

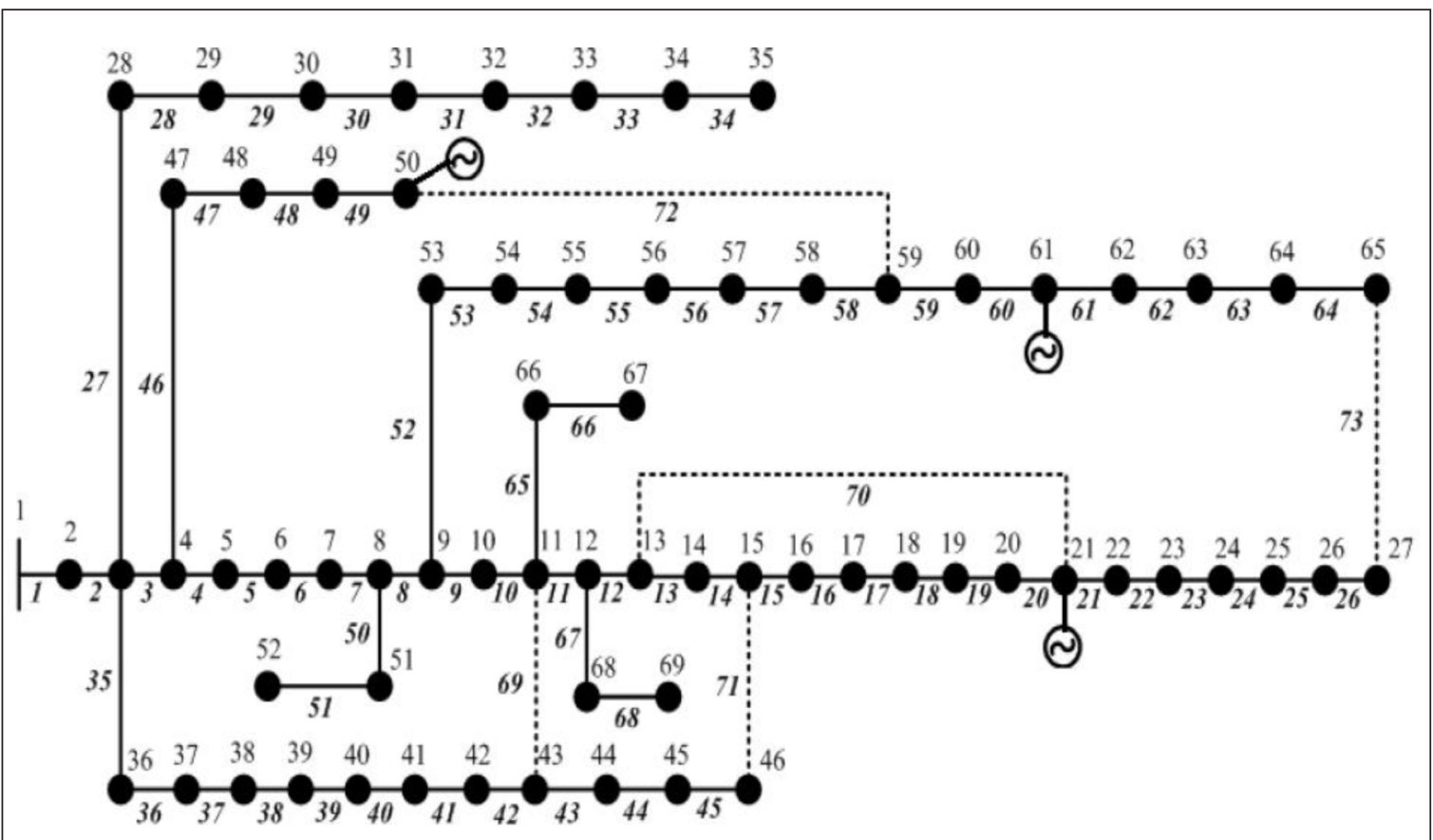

Fig. 5. The distribution network of 69 -nodes 
power loss without connection with DG is $224.95 \mathrm{~kW}$. After performing the new optimized gain algorithm with the open switches $(69,14$, $70,55,62)$, total power losses dropped from $224.95 \mathrm{~kW}$ to $99.75 \mathrm{~kW}$. When introducing DGs into operation, the normally open switches are $(73,72,70,69,71)$ with the total power loss being $274.4 \mathrm{~kW}$. After applying the proposed reconfiguration problem, switches $(69,70,12$, $55,62)$ are opened and the total power losses are reduced from $274.4 \mathrm{~kW}$ to $40.21 \mathrm{~kW}$. Results calculated and compared with previous studies are summarized in Table 5.

\section{Evaluation of emulation results}

The proposed method is compared with the methods proposed by Celli et al. [21], Merlin and Back [7], and Civanlar et al. [9] for the same 16-bus test system, and by Srinivasa et al. [22] for the same 33-bus test system and 69-bus test system. For effective comparison, the results of the proposed method along with other methods are shown. The calculation results in Tables 1 and 2 show that the proposed algorithm found the optimization configuration with the value of power loss smaller than the recommendations in $[9,19]$. The proposed algorithm uses shorter computational time than the existing ones since the calculation takes place once and does not depend on the initial configuration. This algorithm is different from the calculation method [9], in which only one pair of an open/close switch in an independent loop is considered for each calculation, the configuration that has been selected depends a great deal on the initial configuration of the distribution network.

The configuration of the distribution network with and without DG as proposed by algorithm has the same results as TOPO module in PSS/ ADEPT 5.0 (Tables 3-5), but $\Delta P$ decrease smaller than in case of the method proposed by Celli et al. [21], Merlin and Back [7], Civanlar et al. [9] and Srinivasa et al. [22]. The power loss gain function $G$ fully describes the relationship between the electric switches and the branch currents in the distribution network, so all independent loops are considered at once, so the number of operations is small and straight to configuration with minimum $\Delta P$.

The above-described results are calculated with a fixed DG load and capacity. When the DG capacity and load change over time, the process is repeated similarly, so there will be many combinations of switch pairs on the network. This time it is necessary to determine the combination of the switch pair for the smallest $\Delta P$ or to operate with a constant change configuration. As such, accurate information on load forecasting, DG capacity in future times, and the problem of operating the electricity distribution network should be considered in order to reduce damage caused by power failure when re-distributing load.

\section{CONCLUSIONS}

The new heuristic algorithm has been proposed to solve the DNR problem, taking into consideration the value of power loss, resistance factor of the $\mathrm{DN}$, the interaction between switches, and the effects of DG on the distribution network. The paper has developed the explicit expression of the influence of DG on the problem of reconfiguration of the distribution network in order to decrease the total power loss. The new

Table 5. DNR with proposed algorithm in 69-node system

\begin{tabular}{ccccc}
\hline Methods & Power loss (kW) & Open switch & Repeated loop \\
\hline \multicolumn{5}{c}{ The system does not have DG } \\
\hline Initial & 224.95 & $72,73,70,69,71$ & - \\
\hline Proposed method & $\mathbf{9 9 . 7 5}$ & $69,14,70,55,62$ & 24 \\
\hline Srinivasa et al. [22] & 101.32 & $69,14,70,57,61$ & - \\
\hline The system has connection to DG (all 3 DG connected together) \\
\hline Initial & 274.4 & $72,73,70,69,71$ & - \\
\hline Proposed method & $\mathbf{4 0 . 2 1}$ & $69,70,12,55,62$ & 24 \\
\hline Srinivasa et al. [22] & 40.21 & $69,70,12,55,62$ & - \\
\hline
\end{tabular}


objective function $(G)$ is proposed. For this purpose, the configuration of a distribution network is guaranteed to have power loss to be as small as possible, demonstrating the effect of DG on the distribution of current across the distribution network. Function $G$ serves as the basis for the reconfiguration of the distribution network with DG to reduce power loss and is very good for application in online operation.

Due to the characteristics on step-by-step value degradation of the $G$ function, it is possible to develop this function to solve the problems of reconfiguration of the distribution network with DGs such as configuring the distribution network to operate online, power supply restoration, load balancing, and reload redistribution.

The effectiveness of the proposed method is demonstrated on 16-node, 33-node, and 69node distribution networks. Thus, the proposed method can be applied to reconfiguration of any distribution network in reality. The proposed method can be applied to any low- and medium-scale practical radial distribution networks.

Received 11 November 2018 Accepted 18 December 2018

\section{References}

1. Kalambe S., Agnihotri G. Loss minimization techniques used in distribution network: Bibliographical survey. Renewable and Sustainable Energy Reviews. 2014. Vol. 29. P. 184-200.

2. Ghasemi S., Moshtagh J. Radial distribution systems reconfiguration considering power losses cost and damage cost due to power supply interruption of consumers. International Journal on Electrical Engineering and Informatics. 2013. Vol. 5. No. 3. P. 297-315.

3. Milani A. E., Haghifam M. R. A new probabilistic approach for distribution network reconfiguration: Applicability to real networks. Mathematical and Computer Modelling. 2013. Vol. 57. No. 1-2. P. 169-179.

4. Radha B., Rughooputh S. A. Modified genetic algorithm for optimal electrical distribution network reconfiguration. IEEE Conference on Electronic Commerce. 2003. P. 1472-1479.
5. Baran M. E., Wu F. F. Network reconfiguration in distribution systems for loss reduction and load balancing. IEEE Transactions on Power Delivery. 1989. Vol. 4. No. 2. P. 1401-1407.

6. Ameli A., Bahrami S., Khazaeli F., Reza M. A multiobjective particle swarm optimization for sizing and placement of DGs. DG Owner's and Distribution Company's Viewpoints. 2014. Vol. 29. No. 4. P. 1-10.

7. Merlin A., Back H. Search for a minimal-loss operating spanning tree configuration in an urban power distribution system. 5th Power System Computation Conference. 1975. P. 1-18.

8. Shirmohammadi D., Hong H. W. Reconfiguration of electric distribution networks for resistive line losses reduction. IEEE Transactions on Power Delivery. 1989. Vol. 4. No. 2. P. 1492-1498.

9. Civanlar S., Grainger J., Yin H., Lee S. Distribution feeder reconfiguration for loss reduction. IEEE Transactions on Power Delivery. 1988. Vol. 3. No. 3. P. 1217-1223.

10. Kiran Kumar K., Venkata Ramana N., Kamakshaiah S. FDR particle swarm algorithm for network reconfiguration of distribution systems. Journal of Theoretical and Applied Information Technology. 2012. Vol. 36. No. 2. P. 174-181.

11. Ahmadali A., Hamidreza K., Hossein M., Amin H. Optimal allocation of DG by using improved genetic for IEEE 33 Bus systems. Technical Journal of Engineering and Applied Sciences. 2014. P. 29-35.

12. Wazir A., Arbab N. Analysis and optimization of IEEE 33 Bus radial distributed system using optimization algorithm. Journal of Emerging Trends in Applied Engineering. 2016. Vol. 1. No. 2. P. 25184059.

13. Badran O., Mekhilef S., Mokhlis H., Dahalan W. Optimal reconfiguration of distribution system connected with distributed generations: A review of different methodologies. Renewable and Sustainable Energy Reviews. 2017. Vol. 73. P. 854-867.

14. Sultana B., Mustafa M. W., Sultana U., Bhatti A. R. Review on reliability improvement and power loss reduction in distribution system via network reconfiguration. Renewable and Sustainable Energy Reviews. 2016. Vol. 66. P. 297-310.

15. Boum A. T., Ndjependa P. R., Bisse J. N. Optimal reconfiguration of power distribution systems 
based on symbiotic organism search algorithm. Journal of Power and Energy. 2017. Vol. 5. P. 1-9.

16. Mahmoud K., Yorino N., Ahmed A. Optimal distributed generation allocation in distribution systems for loss minimization. IEEE Transactions on Power Systems. 2016. Vol. 31. No. 2. P. 960-969.

17. Gil Mena A. J., Martín García J. A. An efficient heuristic algorithm for reconfiguration based on branch power flows direction. International Journal of Electrical Power and Energy Systems. 2015. Vol. 41. No. 1. P. 71-75.

18. Mohamed Imran A., Kowsalya M., Kothari D. P. A novel integration technique for optimal network reconfiguration and distributed generation placement in power distribution networks. International Journal of Electrical Power and Energy Systems. 2014. Vol. 63. P. 461-472.

19. Thanh N. T., Viet N. A. Electrical power and energy systems distribution network reconfiguration for power loss minimization and voltage profile improvement using cuckoo search algorithm. International Journal of Electrical Power and Energy Systems. 2015. Vol. 68. P. 233-242.

20. Broadwater R. P., Khan A. H., Shaalan H. E., Lee R. E. Time varying load analysis to reduce distribution losses through reconfiguration. IEEE Transactions on Power Delivery. 1993. Vol. 8. No. 1. P. 294-300.

21. Celli G., Loddo M., Pilo F., Abur A. On-line network reconfiguration for loss reduction in distribution networks with Distributed Generation. 18th International Conference and Exhibition on Electricity Distribution, Turin, Italy, 2005. P. 1-4.

22. Srinivasa R. R., Narasimham S. V. L. A new heuristic approach for optimal network reconfiguration in distribution systems. World Academy of Science, Engineering and Technology International Journal of Computer and Information Engineering. 2009. Vol. 3. No. 9. P. 15-21.

23. Castro C. A., Andre Jr., Watanabe A. An efficient reconfiguration algorithm for loss reduction of distribution systems. Electric Power Systems Research. 1990. Vol. 19. P. 137-144.

24. Sarfi R. J., Salama M. M. A., Chikhani A. Y. A survey of the state of the art in distribution system reconfiguration for system loss reduction. Electric Power Systems Research. 1994. Vol. 31. No. 1. P. 61-70.
Ha Duc Nguyen, Ilgiz Mirgalimovich Valeev

\section{SKIRSTOMOJO TINKLO KONFIGŪRAVIMO UŽDAVINIO SPRENDIMO METODŲ GERINIMAS}

\section{Santrauka}

Straipsnyje pateikiami skirstomojo tinklo konfigūravimo uždavinio sprendimo būdai, pagrịsti euristiniais algoritmais. Visų pirma tyrimas išsprendè skirstomojo tinklo konfigūravimo uždavinị aktyviosios galios nuostolių sumažinimui. Metodo taikymas pavyzdiniam tinklui buvo veiksmingas, palyginti su kitais algoritmais, ypač didelès apimties ir sudètingų sistemų atveju. Be to, straipsnyje nagrinejjama paskirstytosios generacijos vietos parinkimo ir galios ittaka skirstomojo tinklo perkonfigūravimui įvairiais atvejais.

Gauti rezultatai rodo, kad skirstomojo tinklo konfigūravimas kartu su paskirstytosios generacijos vietos parinkimu ir galios optimizavimu yra efektyviausias sprendimas mažinant galios nuostolius ir gerinant itampos lygius.

Siūlomi metodai taip pat buvo sèkmingai taikomi mažuose ir vidutinio dydžio realiuose radialiniuose skirstomuosiuose tinkluose. Modeliavimo rezultatai rodo, kad siūlomi metodai gali būti naudojami kaip pavyzdiniai duomenys, skirti tinklo konfigūravimo problemoms spręsti vieno kriterijaus ir daugiakriteriniuose uždaviniuose.

Raktažodžiai: perkonfigūravimas, euristiniai algoritmai, prieaugio funkcija, galios nuostoliai, skirstomasis tinklas 